\title{
Establishment of a quiescent herpes simplex virus type 1 infection in neurally-differentiated PC12 cells
}

\author{
Robert J Danaher ${ }^{1}$, Robert J Jacob² and Craig S Miller*,1,2 \\ ${ }^{1}$ Department of Oral Health Practice, University of Kentucky College of Dentistry, Lexington, Kentucky 40536-0084, USA; \\ ${ }^{2}$ Department of Microbiology and Immunology, University of Kentucky College of Medicine, Lexington, Kentucky 40536- \\ 0084, USA
}

\begin{abstract}
Rat pheochromocytoma (PC12) cells differentiated with nerve growth factor (Nd-PC12) were used to investigate the establishment of a non-productive herpes simplex virus type 1 (HSV-1) infection that is reversible. The results of this work are as follows: (i) Nd-PC12 cultures could be maintained as long term ( $>7$ weeks) non-dividing cultures only when plated on collagen-coated dishes in the absence of serum; (ii) Infection of Nd-PC12 with HSV-1 strains KOS and 17 in the transient presence of acycloguanosine (ACV) resulted in all cultures free of detectable levels of infectious virus at the time of ACV removal and ACV was not needed to maintain the non-productive quiescent state in the subsequent 8 weeks; (iii) These persistently infected and quiescent (QIF)-PC12 cultures demonstrated both spontaneous and forskolin-inducible virus production, at low (5\%) and high frequencies $(92-100 \%)$, respectively during the first 2 weeks post-ACV withdrawal. (iv) In contrast to other in vitro models, HSV-1 failed to reactivate following removal of nerve growth factor. (v) A high percentage of QIF-PC12 cultures (50-100\%) produced virus in response to forskolin treatment as long as 7 weeks post-ACV withdrawal. (vi) Expression of HSV-1 productive genes (i.e. $\alpha 0, \alpha 4, \alpha 27, U_{L} 30$ and $U_{L} 18$ ) dropped precipitously in the presence of $\mathrm{ACV}$ and remained undetectable or continued to decline following its removal, whereas the levels of LAT and the host gene G3PDH remained relatively constant throughout the 31 day study period as measured by RT PCR. These results indicate that QIF-PC12 cells offer a novel, neuronal cell culture system that may enhance our ability to study HSV-1 reactivation from a cryptic, latent-like, non-productive state in the absence of replication inhibitors.
\end{abstract}

Keywords: cell culture model; herpes simplex virus, viral latency

\section{Introduction}

The lack of a universally accepted neural cell-line that supports HSV-1 latency has restricted our understanding of the molecular events involved in reactivation from latency. As a result, animals and tissue culture have served to provide an understanding of the mechanisms of this event. Animal models, however, are limited by difficulties. These include: (i) latency and reactivation events that are influenced by viral strains with different primary growth phenotypes; (ii) the limited number of

*Correspondence: CS Miller, Oral Medicine Section MN 118, Department of Oral Health Practice, University of Kentucky College of Dentistry, 800 Rose Street, Lexington, Kentucky 40536-0084, USA

Received 10 October 1998; revised 2 December 1998; accepted 11 December 1998 neurons latently infected in animal models (Bloom et al, 1996; Hill et al, 1996; Maggioncalda et al, 1996; Mehta et al, 1995; Ramakrishnan 1994; Sawtell, 1997; Sawtell et al, 1998; Thompson and Sawtell, 1997), and (iii) inaccurate quantitation of reactivation events when measuring virus production at the recurrent site as a result of influences of transport, replication in epithelium, and the immune response.

A major advantage of tissue and cell culture models includes the ability to observe virus at the single cell level without the overlay of immunological events that modulate the eventual appearance of virus in the host. Tissue culture models derived from neuronal and sympathetic ganglia have properties of the in vivo system including: (i) restricted transcription of the HSV genome (Doerig et al, 1991; 
Halford et al, 1996; Smith et al, 1992, 1994); (ii) lack of virus production following removal of the inhibitory agent (Wilcox and Johnson, 1988); (iii) the presence of latency-associated transcripts (LATs) (Doerig et al, 1991; Smith et al, 1994); (iv) impaired reactivation of thymidine kinase negative virus (Wilcox et al, 1992), and (v) inducible reactivation (Halford et al, 1996; Moriya et al, 1994; Smith et al, 1992; Wilcox and Johnson, 1987, 1988; Wilcox et al, 1990). Nevertheless, preparation of dissected ganglia is inconvenient, material is limited, animal use is required, and axotomy introduces traumatic factors that influence reactivation of virus.

For the above reasons, cell culture models are important for studying the molecular details of the establishment, maintenance and reactivation stages of latency. Cell culture also allows for an unlimited supply of a defined host cell and the ability to manipulate genetic material. Over the past 25 years, cell culture systems using fibroblast cultures (Harris and Preston, 1991; Jamieson et al, 1995; O’Neill, 1977; O’Neill et al, 1972; Russell et al, 1987; Scheck et al, 1989; Wigdahl et al, 1982a,b, 1983) and lymphocytes (Hammer et al, 1981; Youssoufian et al, 1982) have enabled the study of HSV-1 during a latent-like state. These models, however required low input multiplicities and/or the use of replication inhibitors such as anti-viral agents, inhibitory temperatures, or the use of a mutant virus, to prevent virus production.

A cell line that has neural morphology and physiology, can survive infection and permit HSV1 production, allow establishment of a long term nonproductive HSV-1 infection, and support HSV-1 in a state suitable for reactivation studies would be more desirable. The rat pheochromocytoma (PC12) cell line is a potential candidate because they are of neural crest origin and can be morphologically differentiated with the addition of nerve growth factor (Greene and Tischler, 1976). These cells have been shown to be permissive to HSV-1 infection (Bloom and Stevens, 1994; Rodahl and Haar, 1997; Rubenstein and Price, 1983a,b, 1984), and have been used to examine HSV-1 gene regulation and expression (Frazier et al, 1996a,b; Jordan et al, 1998; Leib et al, 1991; Xie et al, 1996) and the function of HSV origins of DNA replication (Hardwicke and Schaffer, 1997). The relevance of these studies, however remains incomplete since the ability of these cells to harbor HSV-1 in a 'latent-like' state has not been demonstrated (Block et al, 1994).

In this report, we demonstrate that neurallydifferentiated PC12 cells can be infected with HSV-1 in a manner that supports a long term nonproductive infection. This model when compared to others is unique in that (1) quiescent infection is established in a neuronal cell line that has features reminiscent of ganglionic neurons; (2) an artificial inhibitor of DNA synthesis is needed only to establish the quiescent state, not maintain it; (3) an inhibitor of HSV-1 gene expression is not required to establish the quiescent state; (4) the non-productive state is reversible with spontaneous and inducible reactivation, and (5) quiescence is long term. This model should serve as a suitable system for studies of HSV-1 reactivation from a nonproductive state.

\section{Results}

Conditions for maintenance of long term, non-dividing differentiated PC12 cultures

Previous studies have demonstrated NGF-differentiated PC12 (Nd-PC12) cells can be maintained as non-dividing cultures both in the presence and absence of serum (Greene, 1978; Greene and Tischler, 1976). These cultures have been studied on non-coated (Block et al, 1994) and collagen coated dishes (Greene and Tischler, 1976). Preliminary studies in our laboratory, however, indicated that a significant portion of PC12 cells cultured in the presence of serum continued to divide and is consistent with the findings of others (Goodman et al, 1979; Ignatius et al, 1985). Because a differentiated, non-dividing and adherent cell population was desired, we first determined whether continued growth of cells was the result of high plating density that may have exhausted the NGF supplied (Gunning et al, 1981). To make this determination, cells were plated at two different densities on collagen and non-collagen coated dishes. Cells plated at low density were NGF

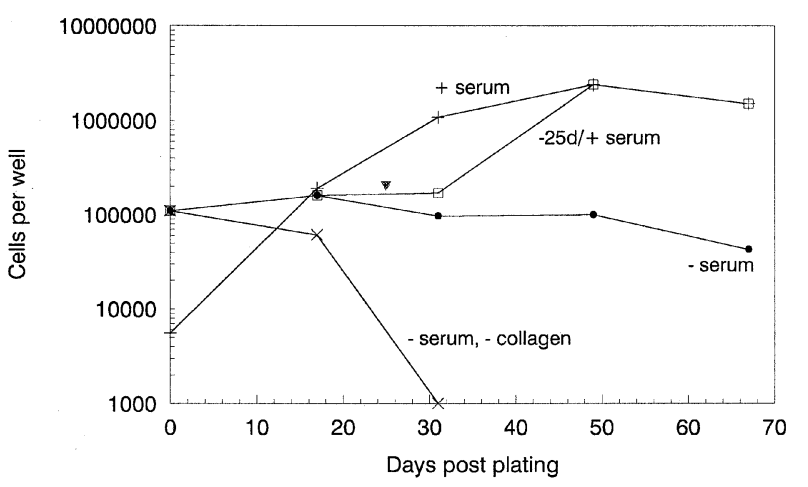

Figure 1 Growth characteristics of long-term cultures of NGF differentiated PC12 cells. PC12 cells were plated at $5.5 \times 10^{3}$ cells (low density) and $1.1 \times 10^{5}$ cells (standard density) per $3.8 \mathrm{~cm}^{2}$ well in RPMI 1640 media with serum in 12-well culture plates. NGF differentiation was initiated by the addition of NGF (50 ng/ml) in RPMI+serum or RPMI+BSA (-serum) for low and standard cell density plates, respectively, 2 days after plating. NGF was maintained throughout the duration of the assay and culture medium was replaced every 2 days. On day 25, postplating, select ( - serum) cultures were switched to RPMI+serum+NGF $(-25 \mathrm{~d} /+$ serum $)$. Cultures maintained on non-collagen coated plates are indicated (- collagen). Each data point represents the average number of cells/well from duplicate wells. 
differentiated in the presence of serum (+serum) whereas those plated at standard density were differentiated in the absence of serum (-serum). Figure 1 shows that Nd-PC12 cells proliferated under serum containing conditions. In collagen coated wells containing media supplemented with serum, the cell density increased more than 30 -fold (i.e. from $5.5 \times 10^{3}$ to $1.9 \times 10^{5}$ cells per well) by 17 days post-plating (p.p.) with an additional 12 -fold increase (to $2.4 \times 10^{6}$ cells per well) in the following 32 days. The cell density of parallel cultures grown on non-coated plates also continued to divide maintaining cell densities of about $50 \%$ of those cultured on collagen-coated dishes (data not shown). When Nd-PC12 cells were grown on coated dishes in the absence of serum ( - serum) a relatively constant cell number was maintained for 7 weeks with a subsequent loss of about $50 \%$ of the cells during the following 18 days. As shown, parallel cultures maintained in serum free conditions did not adhere well to non-coated dishes. The addition of serum to minus-serum Nd-PC12 cultures on day 25 p.p. resulted in a $70 \%$ increase in cell number within 6 days and an additional 14-fold increase in the following 18 days achieving equivalent cell densities as +serum cultures. These data demonstrate that a relatively constant number of Nd-PC12 cells could be maintained as non-dividing cultures only when cultured in the absence of serum and that cell growth arrest is reversible upon the addition of serum to the media for up to 25 days p.p.

\section{Establishment of a quiescent nonproductive infection}

To determine if Nd-PC12 cultures could harbor HSV-1 in a non-replicating state, Nd-PC12 cells were established in serum free conditions. Cells were infected in the presence of acycloguanosine (ACV) on day 7 or 15 following initiation of neural differentiation by NGF with KOS at MOI of $27 \pm 3$ to favor infection of every cell. Cultures were supplemented with ACV since cultures infected in the absence of ACV continued to produce virus for greater than 2 months (unpublished observation; Block et al, 1994). ACV was maintained from day -1 to +9 p.i. as described by Wilcox and Johnson (1988). Under these conditions, all cultures were free of detectable levels of infectious virus in the supernatants at the time of ACV withdrawal and virus was detected in only $4 \%$ of cultures during the 8 days following ACV withdrawal.

To determine whether virus was present in a recoverable form during the period following drug removal, cells maintained in NGF and serum-free media were subjected to forskolin, an activator of adenylate cyclase known to reactivate virus from latently infected tissue (Smith et al, 1992). Figure 2 shows that forskolin treatment resulted in detectable virus in $92 \%$ of 7 -day Nd-cultures and $100 \%$ of 15-day Nd-cultures within 9 days post-treatment,

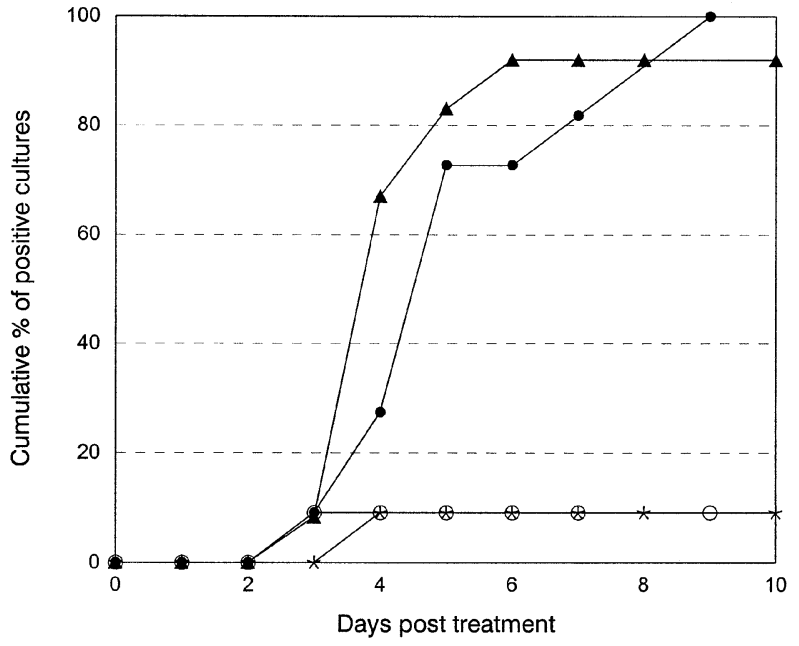

Figure 2 Induced HSV-1 production from quiescent-infected PC12 cell cultures. PC12 cells were plated at $1.1 \times 10^{5}$ cells/ $3.8 \mathrm{~cm}^{2}$ well and maintained in RPMI supplemented with BSA and NGF in 12-well plates. Media was replaced every 2 days. Cultures were infected with KOS at a MOI of $27 \pm 3$ on day 7 and 15 following the initiation of neural differentiation with NGF. ACV $(50 \mu \mathrm{M})$ was maintained in the medium from -1 day to 9 day p.i. Cells were treated with forskolin $(50 \mu \mathrm{M})$ on day 8 postACV withdrawal. Culture medium was analyzed for released virus daily by direct plaque assay and replaced with fresh medium every $2-3$ days. Control cultures infected on day 7 and day 15 p.p. are represented by (* and $\bigcirc)$, respectively. Forskolin-induced cultures infected on day 7 and 15 p.p. are represented by ( $\boldsymbol{\Lambda}$ and $\boldsymbol{0}$ ), respectively.

compared to only one positive well $(9 \%)$ in the untreated infected control sets. Cytopathic effect was not seen microscopically in these reactivating cultures. These findings indicate that a quiescent, nonproductive HSV-1 infection can be established in PC12 cells that have undergone a 7 or 15 day neural differentiation period. In addition, virus persists in Nd-PC12 cells in a recoverable state, and reactivation may be occurring in only a minority of the infected cells.

Reactivation from long-term (50 days) HSV-1 infected, quiescent PC12 cultures

To determine whether Nd-PC12 cells could harbor HSV-1 in a recoverable state for long periods of time following removal of ACV, Nd-PC12 cultures were infected with strain KOS at a MOI of $27 \pm 3$ on day 15 p.p. and maintained as quiescently infected cultures (QIF-PC12) as described in Figure 3. Under these conditions, all cultures were free of detectable levels of infectious virus in the supernatants at the time of ACV withdrawal. Virus was detected in only one of 35 cultures during the following 8 days, and virus was not detected from total cell lysates of four infected control wells on day 16 post-ACV withdrawal (data not shown). To determine if NGF withdrawal would induce virus production, as described by Wilcox and Johnson (1987), NGF was withdrawn on day 8 post-ACV withdrawal. Virus 
was detected by day 8 post-treatment in $100 \%$ of forskolin-induced control cultures, $8 \%$ NGF-free cultures, and $5 \%$ of infected untreated control cultures (Figure 3A). Except for the detection of virus in two of the remaining 14 infected untreated control wells on day 17 post-ACV withdrawal, virus was not detected in infected control wells for the remaining 39 days. To determine whether these virus negative (non-producing) cultures were still capable of producing virus, four of 12 cultures were treated with forskolin on day 38 , and four of eight were treated with forskolin on day 49 post-ACV withdrawal. Induction with forskolin at these later dates resulted in the detection of virus in $75 \%$ and $50 \%$ of cultures, respectively, compared with $0 \%$ in the remaining infected untreated control cultures (Figure 3B and C). These data indicate that virus can be recovered from long-term QIF-PC12 cultures when induced with forskolin.

\section{Detection of viral transcripts during the} establishment and maintenance of the quiescent phase of QIF-PC12 cultures

To study viral gene expression during the establishment and maintenance phases of a quiescent infection, QIF-PC12 cells were established under conditions that minimize the effects of high copy number of viral genomes. This was achieved using strain 17 because it reactivates more efficiently in this model than KOS (data not shown). The infections were performed at an MOI of 0.5. The rate of virus reactivation from QIFPC12 cells established under these conditions are

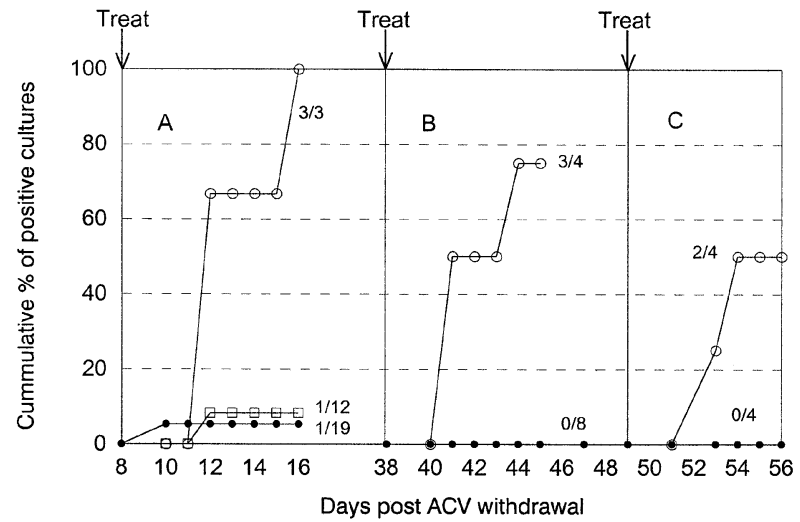

Figure 3 Induction of HSV-1 from long-term QIF-PC12 cells. PC12 cells were plated at $1.1 \times 10^{5}$ cells $/ 3.8 \mathrm{~cm}^{2}$ well in RPMI+serum in 12-well plates. Beginning on day 2 p.p., cells were maintained in RPMI supplemented with BSA and NGF, with media changes every 2 days. Cells were infected with HSV1 strain KOS (M) at a MOI of $27 \pm 3$ on day 15 post plating. Culture medium was supplemented with ACV $(50 \mu \mathrm{M})$ from days -1 to 8 p.i. Cultures were treated as indicated and monitored for released virus as described in Figure 2. Represented are forksolin treated cultures (O), cultures subjected to NGFwithdrawal ( $\square$ ), and control cultures (○). (A) represents treatment on day 8 , (B) represents treatment on day 38 , and (C) represents treatment on day 49. presented in a subsequent manuscript (Danaher et al, 1999).

RNAs from duplicate QIF-PC12 cell cultures were collected at the indicated time points throughout the 31 day period and analyzed by RT-PCR in duplicate. The specificity of the RT-PCR products were confirmed by Southern blot analysis. Primers and probes used in this analysis are shown in Table 1. Figure 4 shows representative results from one of four samples from each time point examining the viral and host genes (G3PDH gene). A precipitous decline in transcripts occurred from the selected representatives of the three classes of the herpes virus genes (i.e. immediate early $[\alpha]$, early $[\beta]$, late $[\gamma]$ ) tested following day 1 p.i. Detection of transcripts from $\alpha$ genes extended to as long as 10 days after ACV removal (i.e. 20 days p.i.), as typified by the $\alpha 4$ product. Transcripts from the $\mathrm{U}_{\mathrm{L}} 30$ (DNA polymerase gene), representing the $\beta$ genes, became undetectable by the day of ACV withdrawal (i.e. day 5 p.i.). Gamma genes, as represented by $\mathrm{U}_{\mathrm{L}} 18$ (VP23), were below the level of detection by day 10 p.i. In contrast to the precipitous decline in all classes of viral gene transcripts represented, the stable LAT transcript persisted, although somewhat reduced compared to day 1 p.i. levels, for the length of the assay. From Figure 4, it is apparent that the products of the representative viral genes, except for LAT, diminished significantly throughout the 31 day period assayed. Expression of the host cell gene G3PDH was constant throughout the time period measured.

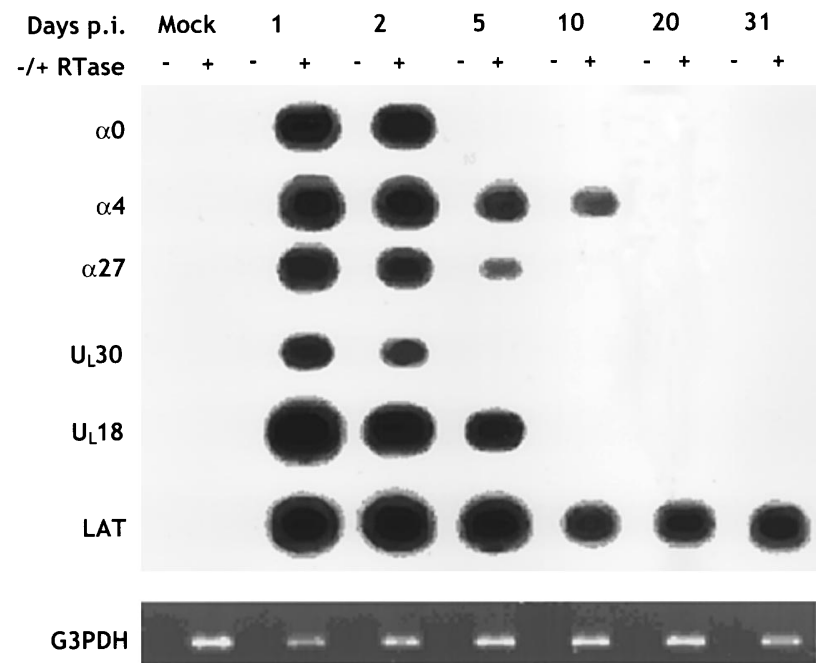

Figure 4 Southern analysis of HSV-1 transcripts produced during the establishment and maintenance of the quiescent phase of infection. PC12 cells were plated at $1.1 \times 10^{6}$ cells/ $9.6 \mathrm{~cm}^{2}$ tissue culture wells in RPMI supplemented with BSA and NGF. On day 4 post plating, media was switched to RPMI+serum supplemented with NGF for 2 days, followed by RPMI supplemented with BSA, NGF and ACV. Cells were infected with HSV-1 strain 17+ at a MOI of 0.5 on the following day and maintained in the presence of ACV $(100 \mu \mathrm{M})$ for 10 days. Duplicate culture wells were collected at the indicated times for RT-PCR analysis. 
Table 1 Primer and probe sequences used to amplify and analyze cDNA obtained from HSV-1 infected PC12 cells

\begin{tabular}{|c|c|c|c|c|c|c|}
\hline Gene & Primer and & robe sequence ${ }^{a}$ & $\begin{array}{l}\text { Sequence } \\
\text { location }^{b}\end{array}$ & $\begin{array}{l}\text { Kinetic } \\
\text { class }\end{array}$ & $\begin{array}{l}\text { Size of PCR } \\
\text { product }\end{array}$ & Reference \\
\hline \multirow[t]{3}{*}{$\alpha 0$} & $\alpha 0-1$ & ACGGACACGGAACTGTTCGAGA & $\leftarrow 123,151$ & $\alpha$ & $262 \mathrm{bp}$ & Nichol et al, 1996 \\
\hline & $\alpha 0-2$ & TGTTGCGCAATTGCATCCAGGT & $122,890 \rightarrow$ & & & Nichol et al, 1996 \\
\hline & $\alpha 0$ probe & CGTCGCCCTCGTCGCTCCCC & $123001 \rightarrow$ & & & This study \\
\hline \multirow[t]{3}{*}{$\alpha 4$} & $\alpha 4-1$ & GGCGGGAAGTTGTGGACTGG & $\leftarrow 127308$ & $\alpha$ & 138 bp & Devi-Rao et al, 1994 \\
\hline & $\alpha 4-2$ & CAGGTTGTTGCCGTTTATTGCG & $127171 \rightarrow$ & & & Devi-Rao et al, 1994 \\
\hline & $\alpha 4$ probe & GTCCCGGCCCGTTACAGCAC & $127221 \rightarrow$ & & & This study \\
\hline \multirow[t]{3}{*}{$\alpha 27$} & $\alpha 27-1$ & TTTCTCCAGTGCTACCTGAAGG & $114922 \rightarrow$ & $\alpha$ & $283 \mathrm{bp}$ & Devi-Rao et al, 1994 \\
\hline & $\alpha 27-2$ & TCAACTCGCAGACACGACTCG & $\leftarrow 115204$ & & & Devi-Rao et al, 1994 \\
\hline & $\alpha 27$ probe & CTGGACGAACTGTGTTCGCG & $114961 \rightarrow$ & & & This study \\
\hline \multirow[t]{3}{*}{$\mathrm{U}_{\mathrm{L}} 30$} & Pol-1 & GAACACGGACTATTACTTCTCC & $66274 \rightarrow$ & $\beta$ & 227 bp & Devi-Rao et al, 1994 \\
\hline & Pol-2 & CAAAGGCTCTATGCAACATTCG & $\leftarrow 66500$ & & & Devi-Rao et al, 1994 \\
\hline & Pol probe & GCGTGCGTGACATTCAAGGC & $66311 \rightarrow$ & & & This study \\
\hline \multirow[t]{3}{*}{$\mathrm{U}_{\mathrm{L}} 18$} & VP23-1 & TGAACCCCAGCCCCAGAAACC & $\leftarrow 35564$ & $\gamma$ & $149 \mathrm{bp}$ & Devi-Rao et al, 1994 * \\
\hline & VP23-2 & CGAGTAAACCATGTTAAGGACC & $35416 \rightarrow$ & & & Devi-Rao et al, 1994* \\
\hline & VP23 probe & CGGCGTTTACGGGACCGAGT & $35451 \rightarrow$ & & & This study \\
\hline \multirow[t]{3}{*}{ LAT } & LAT-1 & GACAGCAAAAATCCCCTGAG & $120702 \rightarrow$ & Latency & $195 \mathrm{bp}$ & Lynas et al, 1989 \\
\hline & LAT-2 & ACGAGGGAAAACAATAAGGG & $\leftarrow 120896$ & & & Lynas et al, 1989 \\
\hline & LAT probe & CGACACGGATGGGCTGGTGT & $120794 \rightarrow$ & & & This study \\
\hline \multirow[t]{2}{*}{ G3PDH } & G3PDH-1 & GAATCTACTGGCGTCTTCACC & & & $239 \mathrm{bp}$ & Halford et al, 1986 \\
\hline & G3PDH-2 & GTCATGAGCCCTTCCACGATGC & & & & Halford et al, 1986 \\
\hline
\end{tabular}

${ }^{a}$ Primer and probe sequences are shown $5^{\prime}$ to $3^{\prime}$. Upstream (mRNA sense) and downstream (mRNA antisense) primers of each set are referred to as 1 and 2 , respectively.

${ }^{\mathrm{b}}$ Location indicates the position of the $5^{\prime}$ base of each oligonucleotide according to the HSV-1 sequence of strain 17 syn+ (McGeoch et al, 1986, 1988; Perry and McGeoch, 1988). Only the locations in the long and short internal repeats are indicated for the LAT, $\alpha 0$, and $\alpha 4$ genes

*Previously published as primer that amplifies $\mathrm{U}_{\mathrm{L}} 19$.

Table 2 Analysis of gene expression during the establishment and maintenance phases of quiescent HSV-1 infection in Nd-PC12 cells

\begin{tabular}{|c|c|c|c|c|c|c|c|}
\hline \multirow[b]{2}{*}{ Gene } & \multirow[b]{2}{*}{ Day 1} & \multicolumn{5}{|c|}{ Average cDNA copies/cell ( \pm standard deviation) } & \multirow{2}{*}{$\begin{array}{l}\text { Limit of } \\
\text { detection }\end{array}$} \\
\hline & & Day 2 & Day 5 & Day 10 & Day 20 & Day 31 & \\
\hline$\alpha 0$ & $4.6(1.9)$ & $3.3(1.7)$ & $0.30(0.26)$ & $0.076^{\mathrm{b}}(0.11)$ & nd & nd & 0.032 \\
\hline$\alpha 4$ & $3.4(2.2)$ & $2.2(1.5)$ & $0.56(0.30)$ & $0.23(0.099)$ & $<{ }^{\mathrm{b}}$ & $<^{\mathrm{c}}$ & 0.078 \\
\hline$\alpha 27$ & $4.4(0.75)$ & $3.1(0.46)$ & $0.48(0.11)$ & $0.098(0.031)$ & $<^{\mathrm{b}}$ & nd & 0.058 \\
\hline $\mathrm{U}_{\mathrm{L}} 30$ & $0.47(0.19)$ & $0.17(0.042)$ & $0.030^{\mathrm{a}}(0.021)$ & nd & $<^{\mathrm{c}}$ & nd & 0.022 \\
\hline $\mathrm{U}_{\mathrm{L}} 18$ & $>1.1$ & $0.80(0.20)$ & $0.32(0.29)$ & $0.015^{\mathrm{a}}(0.010)$ & $0.014^{\mathrm{a}}(0.0084)$ & $<^{\mathrm{b}}$ & 0.010 \\
\hline LAT & $0.12(0.011)$ & $0.12(0.016)$ & $0.067(0.047)$ & $0.056(0.020)$ & $0.049(0.0023)$ & $0.038(0.014)$ & 0.014 \\
\hline G3PDH & $5.5(0.51)$ & $7.2(0.69)$ & $9.8(0.55)$ & $9.2(0.57)$ & $8.2(1.7)$ & $7.4(0.51)$ & \\
\hline
\end{tabular}

cDNA samples from duplicate wells were subjected to amplification by PCR and analyzed by Southern blot (HSV-1 genes) or ethidium bromide staining (host gene) in duplicate. Unless otherwise indicated product was detected in all four samples analyzed. Standard deviations are indicated in parentheses. All PCR reactions of experimental samples were within the linear range except $\mathrm{U}_{\mathrm{L}} 18$ on day 1 p.i.

${ }^{a}$ Product detected in $3 / 4$ samples.

${ }^{\mathrm{b}}$ Product detected in $2 / 4$ samples.

${ }^{\mathrm{c}}$ Product detected in $1 / 4$ samples.

$<$ Indicates that average cDNA copies was less than the limit of detection nd Not detected in any sample.

Table 2 shows the values obtained from duplicate Southern analysis from duplicate cultures at each time point of viral RT - PCR products quantified by densitometry during the 31-day period. The sensitivity in all cases was greater than 0.1 target sequences per cell, with a range of $0.010-0.078$ represented by $\mathrm{U}_{\mathrm{L}} 18$ and $\alpha 4$, respectively. Consistent with the results shown in Figure 4, a precipitous decline in viral transcripts associated with productive infection was determined following day 1 p.i., whereas levels of LAT remained relatively constant. Transcript production from the $\alpha 0$ and $U_{L} 30$ (DNA polymerase gene) declined the fastest during the first 5 days p.i. By day 10 p.i. (day of ACV withdrawal), the level of $\mathrm{U}_{\mathrm{L}} 18$ (VP23) and $\alpha$ gene expression was down $93-99 \%$, and the level of $U_{L} 30$ expression fell below the level of detection. Following the withdrawal of ACV, the expression of these genes continued to decline and by day 20 the average cDNA copies for the $\alpha$ genes were below the level of detection. By day 20 and thereafter, the average cDNA copies for $\mathrm{U}_{\mathrm{L}} 18$ were at the level of 
detection and below. In contrast, LAT transcripts were reduced $53 \%$ by day 10 p.i. but remained relatively constant thereafter, and never dropped near, or below, the level of detection assay. Host G3PDH RNA levels remained relatively constant throughout the assay period. Viral specific product was not detected in uninfected control cultures or in minus reverse-transcriptase controls.

To strengthen the belief that the above analysis was undertaken on cells that were truly quiescent for HSV-1 genome, parallel 12-well cultures, that were determined to be non-productive, were treated with forskolin on day 20 p.i. and reactivated with similar kinetics to that of KOS, as reported in the previous section, with $75 \%$ reactivation by 7 day post-forskolin treatment. This experiment was done under similar conditions described in Figure 2.

\section{Discussion}

Data from the experimental use of rat pheochromocytoma cells presented here indicate that Nd-PC12 cells can be used to establish a long term, nonproductive HSV-1 infection that is reversible. The model is unique in that an artificial inhibitory agent is used to establish, but not maintain, the quiescent infection in a neuronal cell line, and the nonproductive state is long-term, yet reversible with features of spontaneous and inducible reactivation. The reader's attention is turned to the details that support these points.

By applying information reported by Rubenstein and Price (1983a) and Block et al (1994), we found that it was crucial to the establishment of a nonproductive HSV-1 infection that the cultures be: (i) non-dividing; (ii) neurally-differentiated, and (iii) temporally maintained in ACV. Cultures became non-dividing by removing serum from the media and by supplementing the media with NGF (Greene and Tischler, 1976). Despite the absence of serum, neurally-differentiated cells remained viable throughout the 2 month study period as evident by their microscopic appearance and ability to produce virus on treatment (i.e. induction). Maintenance of long-term non-dividing cultures was achieved only when cells were grown in serum-free medium and were plated on collagen-coated dishes.

The antiviral properties of ACV effected the switch to a non-permissive state. We found that ACV treatment for at least 8 days similar to Wilcox and Johnson (1988) resulted in cultures free of detectable levels of virus from all cell lysates and most culture supernatants tested as measured by direct plaque assay after ACV removal. The nonproductive state was established and maintained despite high levels of viral inoculum that favored infection of virtually every cell. This is in contrast to the cell culture models used by Wigdahl et al (1982a,b, 1983) that required low input multiplicity to maintain a non-productive state.

The non-productive state in QIF-PC12 cells reported herein was characterized by the inability to detect virus in cell lysates examined and the vast majority of culture supernatants examined, and infected cells that showed no visible microscopic features of lytic infection. This is in contrast to infection of Nd-PC12 in the absence of ACV that fails to result in a non-productive infection, but instead results in a persistent infection characterized by low level virus shedding as described by Block et al (1994). The ability of ACV to diminish virus replication and allow for the establishment of a quiescent state following its removal is consistent with evidence that processes that limit the acute viral infection favor the establishment and maintenance of a long-term non-productive HSV-1 infection in neurons (Nichol et al, 1996; Wilcox and Johnson, 1988). The fact that ACV was not needed to maintain quiescence is in contrast to previous cell culture models that required the continued presence of inhibitory conditions (O’Neill, 1977; Wigdahl et al, 1982a,b, 1983) or HSV-1 mutants (Harris and Preston, 1991; Jamieson et al, 1995; Russell et al, 1987) to maintain repression of viral growth.

An important finding was that the non-productive HSV-1 infection in Nd-PC12 cells is reversible. It is reversible in that virus is consistently induced and recovered from non-productive QIF-PC12 cultures that show no evidence of residual cell associated virus during the quiescent infection. Induction of virus from these cultures occurs following forskolin treatment. Forskolin has a wide range of effects including activation of adenylate cyclase (Huang et al, 1982; Seamon and Daly, 1981, 1986), activation of viral gene expression (Ikeda et al, 1996), induction of virus reactivation (Smith et al, 1992), and inhibition of voltage-sensitive calcium channels (Park and Kim, 1996). Forskolin induced $50-100 \%$ of non-productive QIF-PC12 cultures to produce detectable levels of released virus for as long as 51 days post-ACV withdrawal (59 days p.i.) from cultures that were free from spontaneous reactivation throughout the study period. This is in concert with the findings of Smith et al (1992) who reported that forskolin induced HSV-1 reactivation from explanted primary fetal sensory ganglia that were latently infected in vitro. Although NGF deprivation resulted in virus production in their tissue culture systems (Wilcox and Johnson, 1987, 1988; Wilcox et al, 1990) and enhanced virus replication in their PC12 system (Block et al, 1994), this treatment failed to release virus from our QIF-PC12 cultures. This suggests that our PC12 model has unique properties for HSV-1 reactivation compared with immature, explanted sensory neurons (Wilcox and Johnson, 1987, 1988; Wilcox et al, 1990) and PC12 cells harboring a low- 
grade chronic infection (Block et al, 1994). Reasons for the difference with respect to the Wilcox et al (1990) model might be explained by the dependence of fetal neurons on neurotrophic factors, requirements for cell viability following axotomy, or different cell types used. Difference in the observations seen between our system and Block et al (1994) could be the result of the altered states of infection in the two models (i.e. quiescence versus shedding).

Changes in gene expression during the establishment and maintenance stages (i.e. following removal of ACV) of the non-productive infection were identified to demonstrate similarities and differences with features reported for latency. Gene expression was examined by synthesizing cDNA from total RNA prepared from cultures terminated on the various days p.i. using RT - PCR. The intent of this analysis was to examine relative changes in the levels of gene expression and to identify times that are free from, or demonstrate low, gene expression that would enhance the significance of reactivation studies. The values reported represent average cDNA copy number generated per cell with an overall sensitivity of greater than $0.1 \mathrm{HSV}-1$ target sequences per cell.

Analysis of HSV-1 gene expression during the establishment of the non-productive state as measured by RT-PCR revealed a precipitous drop in the level of transcription of representative $\alpha(\alpha 0, \alpha 4$ and $\alpha 27), \beta\left(\mathrm{U}_{\mathrm{L}} 30\right)$, and $\gamma\left(\mathrm{U}_{\mathrm{L}} 18\right)$ genes during the establishment phase. This result could be predicted since ACV inhibition of DNA replication reduces HSV-1 productive infection gene expression in neurons (Kosz-Vnenchak et al, 1993) and $\alpha$ gene expression has been shown to peak between 2 and $12 \mathrm{~h}$ p.i. (Bloom and Stevens, 1994; Nichol et al., 1996). The continual decline in productive gene expression after ACV withdrawal (i.e. maintenance phase) is consistent with evidence that initiation of DNA synthesis is a key regulatory event between lytic and latent events (Nichol et al, 1996). The low levels of message by day 10 p.i. (i.e. day of ACV withdrawal) and thereafter was indicative of a quiescence state and that these low levels of gene expression were insufficient to allow the virus to resume the productive cycle. In contrast, levels of LAT transcripts were detected throughout the 31day study period and fell only threefold from day 1 p.i. levels. Although the level of LAT expression was lower than expected, it is consistent with the work of Rodahl and Haarr (1997) who demonstrated that LAT expression requires viral DNA replication in PC12 cells. These findings indicate that the transient treatment with ACV was sufficient to result in low levels, and the shutdown, of $\alpha$ and $\beta$ gene products that favored the establishment of a non-productive state, and that levels of LAT transcripts remained readily detectable during the maintenance phase of infection in Nd-PC12 cells.
In summary, we determined that HSV-1 infection of Nd-PC12 in the temporal presence of ACV results in a non-productive infection that is reversible. These findings were consistent for two HSV-1 strains (KOS and 17). Using strain $17+$ in the presence of ACV, gene expression (i.e. $\alpha 0, \alpha 4, \alpha 27$, $\mathrm{U}_{\mathrm{L}} 30, \mathrm{U}_{\mathrm{L}} 18$ and LAT) was minimal on day 1 p.i. and precipitously declined, except for LAT, throughout the maintenance (i.e. quiescent) phase. Our results indicate that QIF-PC12 cells offer a non-productive and reversible state (i.e. inducible to produce infectious progeny) that should enhance our ability to study processes involved in HSV-1 reactivation from a cryptic, latent-like, non-productive state in the absence of replication inhibitors.

\section{Materials and methods}

\section{Media, cell lines and virus}

Rat pheochromocytoma (PC12) and Vero (African green monkey kidney) cells were obtained from ATCC (Rockville, MD., USA). All culture media and supplements were purchased from Gibco BRL (Gaithersburg, MD., USA) unless otherwise indicated. PC12 cells were grown in RPMI 1640 media containing $5 \%$ fetal bovine serum (FBS) and 10\% heat-inactivated horse serum (HS). Vero cells were grown and maintained in M199 containing 5\% FBS. Cells were incubated at $37^{\circ} \mathrm{C}$ in a humidified incubator with $5 \% \mathrm{CO}_{2}$. All media was supplemented with penicillin (100 units $/ \mathrm{ml}$ ) and streptomycin (100 $\mu \mathrm{g} / \mathrm{ml})$. HSV-1 KOS (M) was a kind gift of $\mathrm{R}$ Thompson (University of Cincinnati, Cincinnati, $\mathrm{OH}, \mathrm{USA}$ ). HSV-1 strain $17+$ was a kind gift of $\mathrm{N}$ Fraser (Wistar Institute, Philadelphia, PA, USA). Viral stocks were prepared in Vero cells and maintained at $-85^{\circ} \mathrm{C}$. Virus production was determined using supernatants from infected cultures in a direct plaque assay (DPA) on monolayers of Vero cells as previously described (Miller and Smith, 1991).

\section{Morphologic differentiation}

PC12 cells were collected from flasks, dissociated by passage through a 22-gauge needle and plated, as indicated in Figure and Table legends, on 6- or 12well tissue culture dishes (Becton Dickinson Labware, Franklin Lakes, NJ, USA) coated with rat tail collagen type 1 (Becton Dickinson), unless otherwise indicated. Collagen was applied as recommended by the supplier. Morphologic differentiation was initiated with $50 \mathrm{ng} / \mathrm{ml}$ of $2.5 \mathrm{~S}$ mouse nerve growth factor (NGF) (Becton Dickinson) in RPMI 1640 media containing 5\% FBS and $10 \%$ HS or RPMI containing $0.1 \%$ bovine serum albumin, fraction V (BSA) as described by Green and Tischler (1976), Green (1978) and Gunning et al (1981). Morphologic differentiation was confirmed by microscopic visualization of dendritic processes. Media was changed every 2-3 days. 
Establishment of a quiescent and persistent infection

Neurally-differentiated PC12 cells (Nd-PC12) were infected with virus, in a volume of 0.4 or $1.0 \mathrm{ml}$ per well, for 12- and 6-well plates, respectively, without agitation at the indicated multiplicity of infection (MOI) overnight at $37^{\circ} \mathrm{C}$. Acycloguanosine (ACV), purchased from Sigma (St. Louis, MO, USA) was added to the medium, at the indicated concentrations, from days -1 to the indicated time post-infection (p.i.). After ACV withdrawal, a quiescent state (i.e. free of detectable infectious virus in culture supernatants and lysates) was maintained for at least 7 days prior to induction.

\section{Reactivation stimuli}

HSV-1 quiescently infected PC12 cells (QIF-PC12), that were free of detectable infectious virus, were subjected to RPMI media containing BSA and NGF supplemented with $50 \mu \mathrm{M}$ forskolin (Sigma) for 2 days at the indicated times. Forskolin was prepared in DMSO (Sigma) as recommended by Huang et al (1982).

\section{RNA isolation and cDNA synthesis}

Cells were harvested for RNA isolation from duplicate wells on the days indicated by scraping cell sheets in PBS followed by centrifugation at 2000 r.p.m. for $5 \mathrm{~min}$. Cell pellets were washed with PBS, pelleted as above and stored at $-85^{\circ} \mathrm{C}$ following removal of PBS. RNA was isolated using the Qiagen RNeasy Total RNA Kit as recommended by the manufacturer. Three $\mu \mathrm{g}$ of each RNA sample was treated with DNAse I (Boehringer Mannheim, Indianapolis, IN, USA) in $20 \mathrm{mM}$ Tris-HCl (pH 8.4), $2 \mathrm{mM} \mathrm{MgCl}_{2}, 50 \mathrm{mM} \mathrm{KCl}$, and 10 Units of RNase-free DNase I in a final volume of $20 \mu \mathrm{l}$ at room temperature for $15 \mathrm{~min}$. DNase I was inactivated by adding $2 \mu \mathrm{l}$ EDTA ( $25 \mathrm{mM}, \mathrm{pH} 8.0)$ and heating at $65^{\circ} \mathrm{C}$ for $10 \mathrm{~min}$. cDNA was generated with SuperScript II reverse transcriptase (Gibco $\mathrm{BRL}$ ) and random primers (Gibco BRL) as recommended by the supplier. cDNA was stored at $-20^{\circ} \mathrm{C}$ until use.

\section{References}

Bloom DC, Stevens JG (1994). Neuron-specific restriction of a herpes simplex virus recombinant maps to the UL5 gene. J Virol 68: 3761-3772.

Bloom DC, Hill JM, Devi-Rao G, Wagner EK, Feldman LT, Stevens JG (1996). A 348-base-pair region in the latency-associated transcript facilitates herpes simplex virus type 1 reactivation. J Virol 70: 2449-2459.

Block T, Barney S, Masonis J, Maggioncalda J, ValyiNagy T, Fraser NW (1994). Long term herpes simplex virus type 1 infection of nerve growth factor-treated PC12 cells. J Gen Virol 75: 2481-2487.
$R T-P C R$

PCR reactions containing $20 \mathrm{mM}$ Tris- $\mathrm{HCl}(\mathrm{pH}$ 8.4), $50 \mathrm{mM} \mathrm{KCl}, 1.5 \mathrm{mM} \mathrm{MgCl}_{2}, 0.2 \mathrm{mM}$ each dNTP, $0.5 \mu \mathrm{M}$ of each primer of the indicated set, 2.5 units Taq DNA polymerase (Gibco BRL) and cDNA derived from 1500 cells were prepared on ice. Samples were denatured at $94^{\circ} \mathrm{C}$ for $3 \mathrm{~min}$ followed by 35 cycles $\left(94^{\circ} \mathrm{C}\right.$ for $45 \mathrm{~s}, 55^{\circ} \mathrm{C}$ for $30 \mathrm{~s}, 72^{\circ} \mathrm{C}$ for $90 \mathrm{~s}$ ), for HSV target sequences, and 26 cycles, for the host target. Control containing tenfold dilutions of HSV-1 DNA ranging from 1.25 fg to $12.5 \mathrm{pg}(7.5-$ 75,000 genome equivalents) or twofold dilutions of PC12 cellular DNA ranging from 0.5 to $4.0 \mathrm{ng}$ (155 to 1240 haploid genome equivalents) were performed in parallel to assess the levels of cDNA in each sample. Experimental and control samples were performed in duplicate and triplicate, respectively. The specificity of viral specific PCR products were verified by Southern blot analysis as described by Brown (1993). In brief, equivalent amounts of PCR products were applied to $2.0 \%$ agarose gels and electrophoresed in $0.5 \times \mathrm{TBE}$ at $50 \mathrm{~V}$ for $45-$ 60 min. DNA was transferred to Magna NT nylon membranes (Micron Separation Inc., Westboro, MA, USA) by capillary action following denaturation and neutralization. Membranes were hybridized to digoxigenin-labeled (DIG Oligonucleotides $3^{\prime}$ end labeling and DIG Luminescent Detection Kits [Boehringer Mannheim]) probes specific for HSV-1 gene sequences (see Table 1). The blots were scanned using the PhosphorImager (Molecular Dynamics, Sunnyvale, CA, USA) and analyzed with GPTools software (Biophotonics, Ann Arbor, MI, USA). Levels of the host glyceraldehyde-3-phosphate dehydrogenase (G3PDH) message were determined for each sample to monitor the reverse transcriptase reaction.

\section{Acknowledgements}

We thank Jun Xie for her technical support. This work was supported by National Institute of Dental Research, National Institutes of Health, grant DE11104 to CSM.

Brown T (1993). Analysis of DNA sequences by blotting and hybridization, 2.9.A-B. In: Current Protocols in Molecular Biology. Ausubel FM, Brent R, Kingston RE, Moore DD, Seidman JG, Smith JA, Struhl K (eds.), Greene Publishing Associates, Inc. and John Wiley \& Sons, Inc.

Danaher RJ, Jacob RJ, Chorak MD, Freeman CS, Miller CS (1999). Heat stress induces reactivation of herpes simplex virus type 1 from quiescently infected neurally differentiated PC12 cells. J Neurovirol (in press). 
Devi-Rao GB, Bloom DC, Stevens JG, Wagner EK (1994). Herpes simplex virus type 1 DNA replication and gene expression during explant-induced reactivation of latently infected murine sensory ganglia. J Virol 68: $1271-1282$.

Doerig C, Pizer LI, Wilcox CL (1991). Detection of the latency-associated transcript in neuronal cultures during the latent infection with herpes simplex virus type 1. Virology 183: $423-426$.

Frazier DP, Cox D, Godshalk EM, Schaffer PA (1996a). Identification of cis-acting sequences in the promoter of the herpes simplex virus type 1 latency associated transcripts required for activation by nerve growth factor and sodium butyrate in PC12 cells. J Virol 70: $7433-7444$.

Frazier DP, Cox D, Godshalk EM, Schaffer PA (1996b). The herpes simplex virus type 1 latency associated transcript promoter is activated through Ras and Raf by nerve growth factor and sodium butyrate in PC12 cells. J Virol 70: 7424-7432.

Goodman R, Chandler C, Herschman HR (1979). Pheochromocytoma cell lines as models of neuronal differentiation. Cold Spring Harbor Conf Cell Proliferation 6: $653-669$.

Greene LA (1978). Nerve growth factor prevents the death and stimulates the neuronal differentiation of clonal PC12 pheochromocytoma cells in a serum-free medium. J Cell Biol 78: $747-755$.

Greene LA, Tischler AS (1976). Establishment of a noradrenergic clonal line of rat adrenal pheochromocytoma cells which respond to nerve growth factor. Proc Natl Acad Sci USA 73: 2424-2428.

Gunning PW, Letourneau PC, Landreth GE, Shooter EM (1981). The action of nerve growth factor and dibutryryl adenosine cyclic $3^{\prime}: 5^{\prime}$-monophosphate on rat pheochromocytoma reveals distinct stages in the mechanism underlying neurite outgrowth. J Neurosci 1: $1085-1095$

Halford WP, Gebhardt BM, Carr DJ (1996). Mechanisms of herpes simplex virus type 1 reactivation. J Virol 70: $5051-5060$.

Hammer SM, Richter BS, Hirsch MS (1981). Activation and suppression of herpes simplex virus in a human T lymphoid cell line. J Immunol 127: 144-148.

Hardwicke MA, Schaffer PA (1997). Differential effects of nerve growth factor and dexamethasone on herpes simplex virus type 1 oriL- and oriS-dependent DNS replication in PC12 cells. J Virol 71: 3580-3587.

Harris RA, Preston CM (1991). Establishment of latency in vitro by the herpes simplex virus type 1 mutant in 1814. J Gen Virol 72: 907-913.

Hill JM, Gebhardt BM, Wen R, Bouterie AM, Thompson HW, O'Callaghan RJ, Halford WP, Kaufman HE (1996). Quantitation of herpes simplex virus type 1 DNA and latency-associated transcripts in rabbit trigeminal ganglia demonstrates a stable reservoir of viral nucleic acids during latency. J Virol 70: $3137-3141$.

Huang RD, Smith MF, Zahler WL (1982). Inhibition of forskolin-activated adenylate cyclase by ethanol and other solvents. J Cyclic Nucleotide Res 8: 385-394.

Ignatius MJ, Chandler CR, Shooter EM (1985). Nerve growth factor-treated, neurite-bearing PC12 cells continue to synthesize DNA. J Neurosci 5: 343-351.
Ikeda Y, Kawaguchi Y, Tomonaga K, Inoshima Y, Kohmoto M, Miyazawa T, Mikami T (1996). Regulatory properties of the integrated long terminal repeat of the feline immunodeficiency virus. Virus Res 41: $201-207$.

Jamieson DRS, Robinson LH, Daksis JI, Nicholl MJ, Preston CM (1995). Quiescent viral genomes in human fibroblasts after infection with herpes simplex virus type 1 Vmw65 mutants. J Gen Virol 76: 1417-1431.

Jordan R, Pepe J, Schaffer PA (1998). Characterization of a nerve growth factor-inducible cellular activity that enhances herpes simplex virus type 1 gene expression and replication of an ICP0 null mutant in cells of neural lineage. J Virol 72: 5373-5382.

Kosz-Vnenchak M, Jacobson J, Coen DM, Knipe DM (1993). Evidence for a novel regulatory pathway for herpes simplex virus gene expression in trigeminal ganglion neurons. J Virol 67: 5383-5393.

Leib DA, Nadeau KC, Rundle SA, Schaffer PA (1991). The promoter of the latency-associated transcripts of herpes simplex virus type 1 contains a functional cAMP-response element: role of the latency-associated transcripts and cAMP in reactivation of viral latency. Proc Natl Acad Sci USA 88: 48-52.

Lynas C, Laycock KA, Cook SD, Hill TJ, Blyth WA, Maitland NJ (1989). Detection of herpes simplex virus type 1 gene expression in latently and productively infected mouse ganglia using the polymerase chain reaction. J Gen Virol 70: 2345-2355.

Maggioncalda J, Mehta A, Su Y-H, Fraser NW, Block TM (1996). Correlation between herpes simplex virus type 1 rate of reactivation from latent infection and the number of infected neurons in trigeminal ganglia. Virology 225: $72-81$.

McGeoch DJ, Dalrymple MA, Davison AJ, Dolan A, Frame MC, McNab D, Perry LJ, Scott JE, Taylor P (1988). The complete DNA sequence of the long unique region in the genome of herpes simplex virus type 1. J Gen Virol 69: 1531-1574.

McGeoch DJ, Dolan A, Donald S, Brauer DHK (1986). Complete DNA sequence of the short repeat region in the genome of herpes simplex virus type 1. Nucleic Acids Res 14: 1727-1745.

Mehta A, Maggioncalda J, Bagasra O, Thikkavarapu S, Saikumari P, Valyi-Nagy T, Fraser NW, Block TM (1995). In situ DNA PCR and RNA hybridization detection of herpes simplex virus sequences in trigeminal ganglia of latently infected mice. Virology 206: $633-640$.

Miller CS, Smith KO (1991). Enhanced replication of herpes simplex virus type 1 in human cells. J Dent Res 70: 111-117.

Moriya A, Yoshiki A, Kita M, Fushiki S, Imanishi J (1994). Heat shock-induced reactivation of herpes simplex virus type 1 in latently infected mouse trigeminal ganglion cells in dissociated culture. Arch Virol 135: 419-425.

Nichol PF, Chang JY, Johnson Jr EM, Olivo PD (1996). Herpes simplex virus gene expression in neurons: viral DNA synthesis is a critical regulatory event in the branch point between the lytic and latent pathways. J Virol 70: 5476-5486. 
O’Neill FJ (1977). Prolongation of herpes simplex virus latency in cultured human cells by temperature elevation. J Virol 24: 41-46.

O’Neill FJ, Goldberg RJ, Rapp F (1972). Herpes simplex virus latency in cultured human cells following treatment with cytosine arabinoside. J Gen Virol 14: $189-197$.

Park T-J, Kim K-T (1996). Cyclic AMP-independent inhibition of voltage-sensitive calcium channels by forskolin in PC12 cells. J Neurochem 66: 83-88.

Perry LS, McGeoch DJ (1988). The DNA sequences of the long repeat region and adjoining parts of the long unique region in the genome of herpes simplex virus type 1. J Gen Virol 69: 2831-2846.

Ramakrishnan R, Fink DJ, Jiang G, Desai P, Glorioso JC, Levine M (1994). Competitive quantitative PCR analysis of herpes simplex virus type 1 DNA and latency-associated transcript RNA in latently infected cells of the rat brain. J Virol 68: 1864-1873.

Rodahl E, Haarr L (1997). Analysis of the 2-kilobase latency-associated transcript expressed in PC12 cells productively infected with herpes simplex virus type 1: evidence for a stable, nonlinear structure. J Virol 71: $1703-1707$.

Rubenstein R, Price RW (1983a). Preservation of catecholamine uptake and release in herpes simplex virus type 1-infected PC12 cells. J Gen Virol 64: $2505-2509$

Rubenstein R, Price RW (1983b). Replication of thymidine kinase deficient herpes simplex virus type 1 in neuronal cell culture: infection of the PC12 cell. Arch Virol 78: 49-64.

Rubenstein R, Price RW (1984). Early inhibition of acetylcholinesterase and choline acetyltransferase activity in herpes simplex virus type 1 infection of PC12 cells. J Neurochem 42: 142-150.

Russell J, Stow ND, Stow EC, Preston CM (1987). Herpes simplex virus gene involved in latency in vitro. $J$ Gen Virol 68: $3009-3018$.

Sawtell NM (1997). Comprehensive quantification of herpes simplex virus latency at the single-cell level. J Virol 71: 5423-5431.

Sawtell NM, Poon DK, Tansky CS, Thomspon RL (1998). The latent herpes simplex virus type 1 genome copy number in individual neurons is virus strain specific and correlates with reactivation. J Virol 72: 53435350.

Scheck AC, Wigdahl B, Rapp F (1989). Transcriptional activity of the herpes simplex virus genome during establishment, maintenance, and reactivation of in vitro virus latency. Intervirology 30: 121-136.

Seamon KB, Daly JW (1981). Activation of adenylate cyclase by the diterpene forskolin does not require the nucleotide regulatory protein. J Biol Chem 256: $9799-$ 9801.
Seamon KB, Daly JW (1986). Forskolin: its biological and chemical properties. Adv Cyclic Nucleotide Res 20: $1-150$.

Smith RL, Escudero JM, Wilcox CL (1994). Regulation of the herpes simplex virus latency-associated transcripts during establishment of latency in sensory neurons in vitro. Virology 202: 49-60.

Smith RL, Pizer LI, Johnson Jr EM, Wilcox CL (1992). Activation of second-messenger pathways reactivates latent herpes simplex virus in neuronal cultures. Virology 188: $311-318$.

Thompson RL, Sawtell NM (1997). The herpes simplex virus type 1 latency-associated transcript gene regulates the establishment of latency. J Virol 71: 54325440 .

Wigdahl BL, Isom HC, DeClercq E, Rapp F (1982a). Activation of herpes simplex virus (HSV) type 1 genome by temperature-sensitive mutants of HSV type 2. Virology 116: $468-479$.

Wigdahl BL, Scheck AC, DeClercq E, Rapp F (1982b). High efficiency latency and activation of herpes simplex virus in human cells. Science 217: 11451146.

Wigdahl BL, Ziegler RJ, Sneve M, Rapp F (1983). Herpes simplex virus latency and reactivation in isolated rat sensory neurons. Virology 127: 159-167.

Wilcox CL, Johnson Jr EM (1987). Nerve growth factor deprivation results in the reactivation of latent herpes simplex virus in vitro. J Virol 61: 2311-2315.

Wilcox CL, Johnson Jr EM (1988). Characterization of nerve factor-dependent herpes simplex virus latency in neurons in vitro. I Virol 62: 393-399.

Wilcox CL, Smith RL, Freed CR, Johnson Jr EM (1990). Nerve growth factor dependence of herpes simplex latency in peripheral sympathetic and sensory neurons in vitro. J Neurosci 10: 1268-1275.

Wilcox CL, Crnic LS, Pizer LI (1992). Replication, latent infection, and reactivation in neuronal culture with a herpes simplex virus thymidine kinase-negative mutant. Virology 187: $348-352$.

Xie K, Knipe DM, DeLuca NA (1996). Role of protein kinase $\mathrm{A}$ and the serine-rich region of herpes simplex virus type 1 ICP4 in viral replication. I Virol 70: $1050-1060$

Youssoufian H, Hammer SM, Hirsch MS, Mulder C (1982). Methylation of the viral genome in an in vitro model of herpes simplex virus latency. Proc Natl Acad Sci USA 79: 2207-2210. 